\title{
PAPER
}

\section{Children's use of gesture to resolve lexical ambiguity}

\section{Evan Kidd and Judith Holler}

\author{
School of Psychological Sciences, The University of Manchester, UK
}

\begin{abstract}
We report on a study investigating 3-5-year-old children's use of gesture to resolve lexical ambiguity. Children were told three short stories that contained two homonym senses; for example, bat (flying mammal) and bat (sports equipment). They were then asked to re-tell these stories to a second experimenter. The data were coded for the means that children used during attempts at disambiguation: speech, gesture, or a combination of the two. The results indicated that the 3-year-old children rarely disambiguated the two senses, mainly using deictic pointing gestures during attempts at disambiguation. In contrast, the 4-yearold children attempted to disambiguate the two senses more often, using a larger proportion of iconic gestures than the other children. The 5-year-old children used less iconic gestures than the 4-year-olds, but unlike the 3-year-olds, were able to disambiguate the senses through the verbal channel. The results highlight the value of gesture to the development of children's language and communication skills.
\end{abstract}

\section{Introduction}

Research on children's use of gesture during language acquisition has identified a tightly coupled relationship between the gestural and verbal systems. Early work by Bates and colleagues identified a key role for deictic gestures as a precursor to the onset of verbal language (e.g. Bates, 1976; Bates, Camaioni \& Volterra, 1975; Bates, Benigni, Bretherton, Camaioni \& Volterra, 1979). Once children begin to acquire their first words, generally at the beginning of their second year of life, they then begin to produce representational gestures, which are indicative of children's burgeoning symbolic sophistication (e.g. Acredolo \& Goodwyn, 1988; Capirci, Contaldo, Caselli \& Volterra, 2005; Capirci, Iverson, Pizzuto \& Volterra, 1996; Iverson, Capirci \& Caselli, 1994; Pizzuto \& Capobianco, 2005; for a review see Capone \& McGregor, 2004). Just as deictic gestures act as precursors to children's initial acquisition of single words, children combine representational gestures with speech before they produce two-word utterances (Capirci et al., 2005; Iverson \& Goldin-Meadow, 2005; McEachern \& Haynes, 2004; Özçalişkan \& GoldinMeadow, 2005, 2009; Pizzuto \& Capobianco, 2005). These results suggest a developmental pattern where gesture marks the onset of milestones in children's early language development, whereby gestures seem to function as a 'transitional device' (Iverson \& Goldin-Meadow, 2005).

Gesture has therefore been shown to precede and facilitate early verbal language development. Furthermore, longitudinal research has shown that once children begin to consistently produce two-word utterances, they produce proportionally fewer gesture-speech combinations due to a rise in the use of speech-only utterances (see Capirci et al., 2005; Pizzuto \& Capobianco, 2005). ${ }^{1}$ Gesture-only utterances, however, decrease and tend to almost completely disappear as children develop. Capirci and Volterra (2008) suggest that this gradual transition from gesture to speech provides ontogenetic support for the proposal that language gradually evolved from a manual-gestural system to a vocal-acoustic one (Corballis, 2002; Gentilucci \& Corballis, 2006), a suggestion that is supported by the fact that motor neurons that control for hand and mouth movement share a common neural substrate (see Kohler, Keysers, Umilità, Fogassi, Gallese \& Rizzolatti, 2002; Rizzolatti \& Arbib, 1998).

Children, of course, do not abandon the use of gesture once they begin to rapidly acquire vocabulary. Mayberry and Nicoladis (2000), for instance, showed that 3-5-yearold children's gesture frequency tends to increase with increasing utterance length, and that their use of iconic gestures predicts their spoken language development. This supports the idea that gesture and speech form an integrated system and that gesture continues to play an important role even in children's later language and cognitive development. A number of studies that have tested older children, aged 5 to 10 years, have provided empirical evidence for this idea. When children in this

\footnotetext{
${ }^{1}$ The story is different for children exposed to sign language (see Capirci, Montanari \& Volterra, 1998; Capirci, Iverson, Montanari \& Volterra, 2002).
} 
age range are asked to complete cognitively demanding tasks their gestures often reveal implicit conceptual knowledge that they do not yet express verbally. Such effects have been shown when children complete Piagetian conservation tasks (e.g. Broaders, Cook, Mitchell \& Goldin-Meadow, 2007; Church \& Goldin-Meadow, 1986), explain solutions to mathematical problems (e.g. Perry, Church \& Goldin-Meadow, 1988), and explain balance tasks (Pine, Lufkin \& Messer, 2004). These studies provide further evidence for the intimate connection between cognition, gesture, and verbal language.

There are several explanations for why children tend to express knowledge in gesture before they do so in speech (see also Goldin-Meadow, 2002). For example, one hypothesis is that more sophisticated language users within the child's social environment are sensitive to gestural signals and alter their interaction with the child and the information they provide accordingly (e.g. GoldinMeadow \& Singer, 2003; Iverson \& Goldin-Meadow, 2005; Pine et al., 2004). This, in turn, may enhance learning. Another explanation is that gesture may facilitate learning by externalizing implicit knowledge that children are not yet expressing verbally; representing implicit knowledge in gesture may result in children noticing the information they represent in their gestures (e.g. Broaders et al., 2007). This may in turn provide an impetus for representational redescription, whereby implicit knowledge becomes increasingly available to conscious reflection, thereby becoming explicit (KarmiloffSmith, 1985). A further hypothesis is that distributing information over two modalities reduces cognitive load, thus freeing up cognitive capacities (e.g. Alibali, Kita \& Young, 2000; Goldin-Meadow, Nusbaum, Kelly \& Wagner, 2001; Thurnham \& Pine, 2006).

In the current study we investigated a phenomenon in children's language acquisition that until now has not considered the role of gesture: children's ability to resolve lexical ambiguities. Our study contributes to the literature on children's use of gestures during later language development, between the ages of 3 and 5 years, a period in which important cognitive and linguistic developments are taking place, but also a period in which children's gestural development has not been extensively studied. Following work on adults' use of gesture to resolve lexical ambiguity (Holler \& Beattie, 2003), we investigated the development of children's use of gesture when attempting to explain different homonym senses (words that have two or more unrelated senses, e.g. bat, bank). We report a sharp developmental trend in children's use of different gesture types to resolve ambiguity attributed to homonymy, which we argue reflects children's emerging metalinguistic awareness and their better ability with age to adopt the perspective of their interlocutor. We next briefly review the past literature on the acquisition of homonymy, and make an argument to study this phenomenon in a context where children can reveal their knowledge of different homonym senses using both gesture and speech.

\section{The acquisition of homonymy}

It has generally been argued in the child language acquisition literature that children prefer to make one-to-one form-meaning mappings during word learning (e.g. Clark, 1993; Markman, 1990). Therefore, lexical ambiguity, which abounds in natural languages, presents a potentially difficult problem to the language learner (e.g. Kidd \& Cameron-Faulkner, 2008). Not only does ambiguity provide a learnability problem, it also presents a communication problem. That is, children not only have to make one-to-many form-meaning mappings, they must also appreciate that interactions must be informative enough to ensure that ambiguous terms map onto their intended referents.

Previous research that has investigated the acquisition of homonyms has shown that young children do not begin to consistently accept non-dominant senses until around 4 years (e.g. Backsheider \& Gelman, 1995; Doherty, 2000; Garnham, Brooks, Garnham \& Ostenfeld, 2000; Peters \& Zaidel, 1980). These studies required children to identify different senses of homonyms from an array of pictures. Doherty (2000) showed that the ability to successfully complete these tasks was related to children's theory of mind ability, although this was disputed by Garnham et al. (2000), who argued that children's developing executive functioning abilities enable them to override the tendency to accept only dominant senses. Regardless of the precise nature of the explanation, these data suggest that children require a degree of metacognitive flexibility in order to explicitly judge multiple form-to-meaning mappings.

Other studies that have investigated children's ability to detect lexical ambiguity have shown that children do not begin to do so until they are around 6 years of age (Cairns, Waltzman \& Schlisselberg, 2004; Keil, 1980; Shultz \& Pilon, 1973). In these studies children were presented with an ambiguous word in a sentential context (e.g. The children saw the bat lying by the fence) and were required to provide the word's two possible meanings. These tasks are explicitly metalinguistic: they require children to reflect upon the dual meaning of the homonym and to reanalyse the sentence, a skill at which preschool children are not adept (Trueswell, Sekerina, Hill \& Logrip, 1999). Not surprisingly, spontaneous detection of the ambiguity is not common in young children, potentially because any awareness of the ambiguity is not available to conscious reflection (Karmiloff-Smith, 1985, 1986), and because the sentential contexts often bias one interpretation over another.

\section{Gesture as a window into children's knowledge of lexical ambiguity}

The previous research on homonym acquisition is characterized by the fact that children have been required to make explicit judgments about the acceptability of different senses in decontextualized circumstances or 
biased contexts. In the current study we were interested in children's emerging ability to resolve ambiguity during a communicative situation that is closer to the problems ambiguity might present in everyday conversation. Thus we were interested in children's awareness of lexical ambiguity as communicatively problematic, and the kinds of strategies that children use to resolve lexical ambiguity during development. ${ }^{2}$

Children could potentially resolve ambiguity using either the verbal or gestural channel, or both. With respect to verbal disambiguation, children could modify homonyms if they have mastered nominal modification. In English, two forms of nominal modification are available: adjectival modification (e.g. the cricket bat), and relativization (e.g. the bat that you use for cricket). Children certainly use these forms of modification by the age of 3 years, and have mastered them by 5 years (for adjectives see Branigan, McLean \& Jones, 2005; Kemp, Lieven \& Tomasello, 2005; Mintz \& Gleitman, 2002; for relative clauses see Diessel, 2004; Kidd, Brandt, Lieven \& Tomasello, 2007), although the extent to which their knowledge is fully abstract early in development has been debated (cf. Branigan et al., 2005; Kemp et al., 2005).

Alternatively, children could attempt to disambiguate homonym senses with the aid of gesture. Once they have started to speak, normally developing children rarely use gesture alone to communicate (e.g. Capirci et al., 2005); therefore we suggest that they would be more likely to accompany verbal attempts to disambiguate with gesture, if they use gesture at all. When children are still in the process of learning to grasp the concept of homonymy and the potential communication problems lexical ambiguity poses for the listener, they may attempt to disambiguate lexical ambiguity using speech and gesture by expressing semantic information also through the gestural channel. For instance, to distinguish a cricket bat from a flying bat, they could use the word bat, accompanied by a hitting action that simulates the use of a cricket bat, an iconic gesture (McNeill, 1992). Unlike conventional language, which is largely rule-bound, componential, and arbitrary, gesture provides a holistic analogue signal that can benefit from iconic mappings onto real world concepts. Therefore we suggest that, for children who find verbal disambiguation difficult, gesture may provide a crucial disambiguating tool, just as in early language development it provides a scaffold from which children can begin to combine words into multiword utterances, or express knowledge which they are not yet able to express explicitly in speech.

\footnotetext{
${ }^{2}$ By 'resolution' we mean an unambiguous representation of the intended concept. Whether or not avoiding ambiguity is intended to aid the listener or the speaker is an open question. Ferreira, Slevc and Rogers (2005) showed that adult speakers sometimes avoid producing ambiguous bare homophones in ambiguous contexts, but that they do not always reliably do so. Their results suggest that speakers only become aware of the ambiguity, and therefore begin the resolution process, once they have produced an ambiguous form.
}

In the current study we investigated 3-5-year-old children's developing ability to resolve lexical ambiguity via speech, gesture, or a combination of the two. The children were told three short stories that contained homonym pairs and at the same time were shown corresponding pictures in a storybook. They were then required to re-tell the story to a second experimenter, who sat behind an occluding screen so that they could see the child but not the storybook. Therefore the occluding screen required the children to resolve the lexical ambiguity for the listener, who could not see the pictures of the two different concepts signified by the homonym. We hypothesized that (i) children would be better able to resolve the lexical ambiguity with age (both in terms of more successful verbal disambiguations and more successful gestural representations), and (ii) before children were capable of competently resolving lexical ambiguity in the verbal channel they would use a combination of gesture and speech, such that younger children would produce more gestures than older children.

\section{Method}

\section{Participants}

Sixty-one $(N=61)$ children aged 3;0-5;11 participated. The sample was divided into three age groups: 3 -year-olds ( $n=25, M=3 ; 5, S D=3.6$ months, range: 3;0-3;11), 4year-olds $(n=17, M=4 ; 7, S D=2.7$ months, range: $4 ; 3-4 ; 11)$, and 5-year-olds $(n=19, M=5 ; 3, S D=3.1$ months, range: $5 ; 1-5 ; 11)$. The children were recruited from two primary schools in the Greater Manchester Area, UK, and from a database of children at the Max Planck Child Study Centre, the University of Manchester.

\section{Materials}

Three story books were constructed. Each contained four hand-drawn pictures. The stories all involved a central character or characters who, during the course of the story, came into contact with the target homonym pair. Each member of the pair was introduced separately on pages 2 and 3 of the story, respectively. On the final page the two homonym senses came into conflict with each other in some way. The story for the homonym bat is presented in Table 1; the stories for the other homonyms (mouse, glasses) are presented in the Appendix.

Each story introduced both homonym senses as ambiguous nominals in order to present an ambiguous situation in the final scene, where the two senses were placed in conflict, such that they could be used in a single sentence.

The children sat at a low table next to one experimenter. A barrier was placed on the table to prevent a second experimenter from seeing the pictures in the storybooks. A video camera (Panasonic NV-GS17) was used to record the children's speech and any gestures they used. 
Table 1 Text for 'Bat' homonym story

\begin{tabular}{ll}
\hline Page & Picture description \\
\hline 1 & $\begin{array}{l}\text { Gary went to the park with his dad. } \\
2\end{array}$ \\
They were playing cricket with Gary's favourite bat (cricket \\
bat). \\
Suddenly, a bat (mammal) appeared above them stopping the \\
game. \\
$\begin{array}{l}\text { So they could carry on playing, Gary's dad tried to hit the bat } \\
\text { with the bat. }\end{array}$ \\
\hline
\end{tabular}

\section{Procedure}

The children were tested individually either in a quiet area of their school or in the Max Planck Child Study Centre at the University of Manchester (where parents were present in the testing room but did not participate in the task). Before commencing, the two experimenters engaged the children in a number of short games so that they would feel comfortable during the experiment. After these warm-up games the second experimenter left the room. The children sat next to the first experimenter, who explained to them that they were going to play a game with stories. It was explained that the first experimenter would tell a story to the child, who would then have to tell the story to the second experimenter, who was now not in the room but loved to hear new stories. Upon the child's approval to proceed, the first experimenter told the child the first story. It was stressed to the child that they would have to listen carefully because they would have to tell the story to the second experimenter. At the end of each story the child was provided with the option to hear it again, and most took advantage of this opportunity. Once the child was confident they could re-tell the story, the second experimenter was called into the room, and sat opposite the child and the first experimenter. A barrier between the second experimenter and the child and first experimenter prevented the second experimenter from seeing the pictures. The child then re-told the story.

In general, the children did not spontaneously disambiguate the homonym senses, presumably because the first experimenter had told the story to them using the ambiguous labels. A series of prompts was used to elicit disambiguations from the children. The second experimenter always began with a recast of the child's final utterance to highlight the ambiguity. For instance, for the story involving the homonym bat, if the child said 'he hit the bat with the bat', the experimenter said, 'he hit the bat with the bat? I don't understand, which bat did he hit with which bat?' (italics denote stress). If the children still did not disambiguate between the two senses, the experimenter asked for clarification by asking what types of (e.g.) bats were in the story. After the child had completed telling the story, and the ambiguity had been resolved to some degree or the experimenters felt that the child would not do so, the child was praised and the second experimenter exited the room so that the first experimenter could read the child the next story. The procedure was repeated this way for all three stories. The presentation of the stories was counterbalanced.

\section{Analysis}

The children's verbal and gestural behaviour was transcribed in detail; however, only children's attempts at disambiguating the ambiguity at the end of the story were analysed. Instances in which verbal utterances were inaudible and/or in which gestures were either not fully visible or unclassifiable were excluded from the analysis. The children mainly produced iconic and deictic gestures (McNeill, 1992). Iconic gestures are defined as gestures that represent semantic information, referring to a concrete concept, in an imagistic manner. The deictic gestures were simple pointing gestures. In the present data set, all pointing gestures were directed at objects and persons in the child's immediate environment; other kinds of deictic gestures, such as 'requesting' or 'showing' (Bates et al., 1979), did not occur. Metaphoric gestures, which are imagistic representations of abstract concepts, were not observed. This is partly due to the concrete nature of the story content, and partly due to the age range of the children who took part (for an overview of the age ranges in which children start to use different kinds of gestures, see McNeill, 1992). Since we were interested in the semantic information the children conveyed relating to the two homonym senses, gestures not representing any semantic information, such as beats, which are tied to the rhythmical patterns of speech, were excluded from the analysis. We also excluded any bodily movements that do not typically form part of the speaker's intended communicative expression, such as self-adaptors (see Ekman \& Friesen, 1969). Two coders identified and categorized all iconic and deictic gestures independently. The inter-observer reliability was $86.03 \%$.

The responses to the experimenter's question that required the children to clarify the two different meanings of the homonym were categorized according to the modalities the children drew upon when attempting to disambiguate (i.e. speech only, gesture only, or speech and gesture). The three main categories were subdivided further into (1) speech only, (2) gesture only (iconic), (3) gesture only (deictic), (4) speech + gesture (iconic), (5) speech + gesture (deictic).

Each reference to either of the two alternative meanings of the homonym was counted as one disambiguation attempt (cf. Holler \& Beattie, 2003). For example, in the verbal channel, children either attempted to clarify a respective meaning by offering a synonym or near synonym (e.g. 'spectacles', 'cups' [successful attempts]), or defined or described the concept using syntactic modification (e.g. 'the living mouse', 'the bat that comes out at night', 'the glasses that you drink from' [successful attempts], 'the glasses that are round' [unsuccessful attempt]). In other cases children avoided using the homonym but 
referred to one meaning using a pronoun ('the dad hits it with the bat', 'he sits on the mouse'). All of these instances were classed as disambiguation attempts, as they were used in the context of clarifying the two different concepts to which each homonym sense referred. Pronouns were not considered to be successful disambiguation attempts as they could have referred to either of the two concepts in most of the cases, or to other characters or objects in the story.

When using gesture, children either pointed (e.g. to the book, a particular object in the picture, or to things in their surroundings, including their own body-parts) or used iconic gestures (i.e. they represented meaning imagistically, for example, by pretending to hold a cricket bat and hitting something, by pretending to hold an imaginary glass, or by arching the hand, with the palm pointing downwards, and moving it around on a horizontal plane, as if using a computer mouse). Whenever a gesture occurred, it usually either corresponded to one verbal attempt (classed as 'speech + gesture') or occurred without speech (classed as 'gesture only'). However, in the case of some deictic gestures, children sometimes left their finger pointing at a referent in the picture while the experimenter asked for further clarification, and started another disambiguation attempt that was still accompanied by the same pointing gesture. That is, in some cases one pointing gesture 'spanned' more than one verbal disambiguation attempt. This was categorized as a separate attempt to disambiguate using speech and gesture. The numbers reported in the subsequent results section are therefore disambiguation attempts accompanied by gesture (note that this number is therefore not exactly the same as the number of gestures used).

A second data set was also created that included only the successful disambiguations (i.e. a subset of the main data set that included all disambiguation attempts). Both iconic and deictic gestures could be used by children in a disambiguating or a non-disambiguating manner. For example, a child might refer to the bat ('the mammal') with the words 'the bat that can fly', accompanied by a gesture where the arms represent wings moving up and down. In this case, both the speech and the iconic gesture would be counted as successfully disambiguating the respective meaning (i.e. the mammal bat). However, another case involved the child referring to glasses (as in cups) by saying 'the round ones', accompanied by a gesture where the outstretched index finger drew an imaginary circle in the air. In this case, neither the speech nor the iconic gesture would be counted as successful attempts because the feature of being round fits both alternative meanings of glasses. Equally, pointing gestures were often used in a manner that did not benefit the disambiguation of the meaning; that is, whenever the children pointed at the picture book that their addressee could not see. However, in some cases, children pointed at, for example, their face to refer to 'seeing glasses'. On one other occasion, one participant pointed to her mother's T-shirt, which had Minnie
Mouse printed on it, to clarify that she was talking about the type of mouse that is an animal. Therefore some deictic gestures were classed as disambiguating. Furthermore, in cases in which a child produced disambiguating speech accompanied by a gesture that had no disambiguating qualities (or vice versa), the attempt was counted as successful. This was also the case when disambiguating information was produced in both gesture and speech. Unsuccessful attempts therefore mean that the child produced neither disambiguating speech nor a disambiguating gesture.

With respect to both data sets, first, the total number of disambiguation attempts made by each child per story was counted (i.e. including gesture only, speech only, and gesture + speech). All other values were calculated by dividing the total number of occurrences in the respective category by the total number of disambiguation attempts made (i.e. all values ranged between 0 and 1). This was done to control for the fact that some children had been asked more questions by the experimenter than others or made repeated attempts to disambiguate of their own accord, and because there were different numbers of children in each age group. Finally, an overall score was calculated by averaging across the three different stories to obtain one data point for each child per category.

It is important to note that we did not limit the amount of disambiguation attempts allowed to the children. The reason for this was that our task was explicitly communicative: we tried to interact with the children as naturally as possible while at the same time retaining control over the questions asked and the kind of opportunities provided for disambiguation. We therefore prompted the children, in all age groups, until they either provided successful disambiguations or until it was clear that they would not succeed in the task, even in response to further prompts. ${ }^{3}$ This way, we offered the younger children sufficient opportunity to disambiguate, even if they needed longer to understand what we wanted them to do. The older children often provided successful disambiguations early on in the process, at which point we stopped prompting them further. The reason for this was that it appears interactionally and pragmatically odd to repeat requests regarding something for which the children had just provided an appropriate answer. Furthermore, gestures are an integral part of, and are directly shaped by, social interaction (Bavelas, 2005; Kendon, 1985). Therefore, gestural behaviour elicited in very constrained or artificial interactions might not be representative of the gestures we observe in everyday interaction.

\footnotetext{
${ }^{3}$ The mean number of prompts each child was asked across the three stories was 23.3 for the 3-year-olds, 11.4 for the 4 -year-olds, 9.9 for the 5 -year-olds. This clearly shows that the 3 -year-olds had a problem with negotiating the ambiguity, whereas the 4- and the 5-year-olds required considerably less and an about equal number of prompts.
} 


\section{Results}

Non-parametric tests were used because the data were not normally distributed. Omnibus Kruskal-Wallis tests were two-tailed and based on an alpha level of .05. Posthoc Mann-Whitney $U$-tests for pair-wise comparisons between the age groups to identify the source of these differences used an adjusted alpha level of $\alpha=.017$ (i.e. $\alpha=.05 / 3$ ) to correct for the inflation of experimentwise error. These post-hoc comparisons were one-tailed, following our directional hypotheses.

The main aim was to test whether children at the ages of 3, 4 and 5 years differ in the way they attempt to disambiguate homonyms. We first discuss children's disambiguation attempts, and then discuss children's successful disambiguations.

\section{Children's use of speech and gesture during disambiguation attempts}

The manner in which children attempted to disambiguate the homonym pairs (i.e. speech only, gesture only, and speech + gesture) is shown in Figure 1 .

Figure 1 shows that the means with which children attempted to disambiguate the homonym senses changed across development. Whereas speech-only attempts increased across development, gesture-only and gesture + speech attempts decreased. Kruskal-Wallis tests showed that the three age groups differed with respect to the number of disambiguation attempts made exclusively using speech $\left(\chi^{2}=17.02, d f=2, p<.0001\right)$. Post-hoc Mann-Whitney $U$-tests revealed that the 3 -year-old children made significantly less speech-only attempts than did the 5-year-old children $\left(U=80.00, n_{1}=25\right.$, $n_{2}=19, p<.0001$ ), and the 4-year-old children made significantly fewer speech-only attempts than did the 5year-old children ( $\left.U=75.00, n_{1}=17, n_{2}=19, p<.003\right)$. The difference between the 3- and 4-year-olds was not significant $\left(U=137.00, n_{1}=25, n_{2}=17, p<.027, n s\right)$.

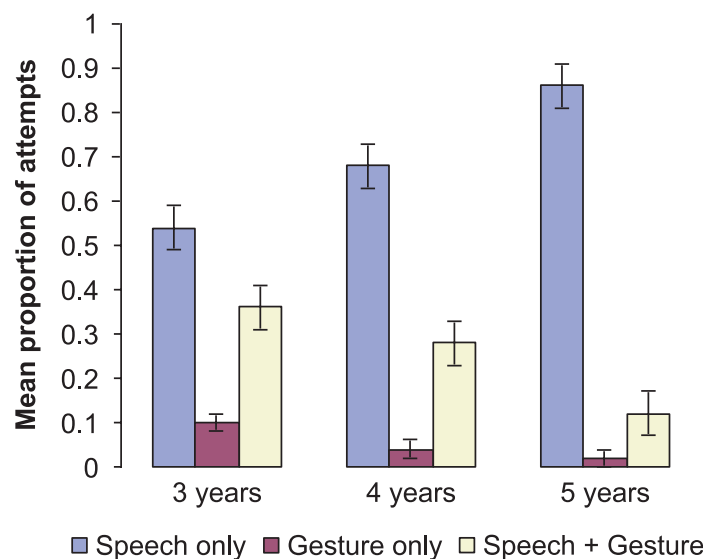

Figure 1 Children's mean proportional use of gesture and/or speech when attempting to disambiguate homonym meanings by age (error bars show standard error).
The children also differed in the number of attempts for which they used only gesture to resolve the ambiguity $\left(\chi^{2}=13.26, d f=2, p<.001\right)$, as well as the number of attempts for which they used both speech and gesture $\left(\chi^{2}=11.04, d f=2, p<.004\right)$. Since we were interested in the children's use of different gesture types, we analysed the children's use of deictic and iconic gestures separately. Figure 2 shows the proportion of disambiguation attempts where children used only deictic or only iconic gestures, for each age group. Figure 3 shows the proportion of disambiguation attempts where children used either speech accompanied by deictic gestures or speech accompanied by iconic gestures, for each age group.

Figure 2 shows that the children's use of deictic gestures as the sole means of disambiguation decreased with age, but that the children's use of iconic gestures did not. Kruskal-Wallis tests showed that the three groups differed in the amount of attempts in which they used only deictic gestures in their attempts to disambiguate $\left(\chi^{2}=15.34, d f\right.$ $=2, p<.0001)$. Mann-Whitney $U$-tests showed that the 3 -year-old children attempted to disambiguate using deictic gestures in the absence of any speech significantly more often than the 4- and 5-year-old children $(U=$ $119.00, n_{1}=25, n_{2}=17, p<.012 ; U=102.50, n_{1}=25$, $\left.n_{2}=19, p<.0001\right)$. The difference between the $4-$ and the 5-year-old children was not significant ( $U=124.50$, $\left.n_{1}=17, n_{2}=19, p<.244, n s\right)$. No significant difference was found between the children's use of iconic gestures as the only means of disambiguation $\left(\chi^{2}=0.11\right.$, $d f=2, p<.473, n s)$, but only very few cases occurred in this category overall (namely, three cases in the entire dataset).

Figure 3 shows that the children's use of deictic gestures that were accompanied by speech decreased with development. In contrast, the children's use of iconic gestures that were accompanied by speech showed an inverted U-shaped trend. That is, the frequency of this style of disambiguation attempt increased from 3 to 4 years, but decreased from 4 to 5 years. Kruskal-Wallis

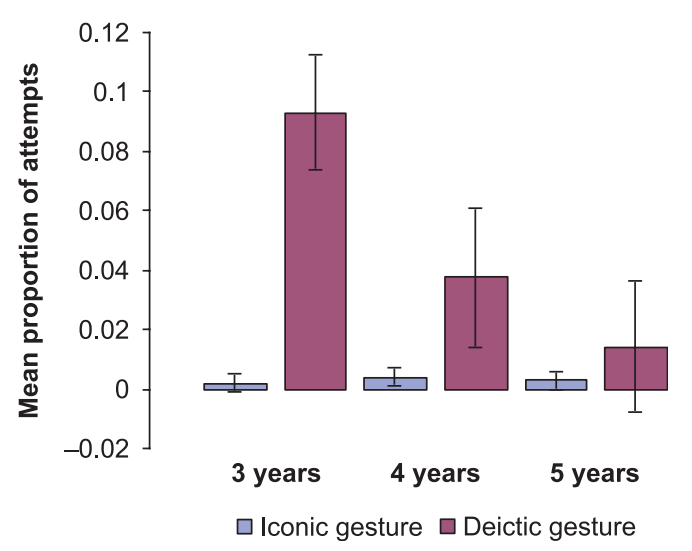

Figure 2 Mean proportion of disambiguation attempts made using only deictic or only iconic gestures in the three age groups (error bars show standard error). 


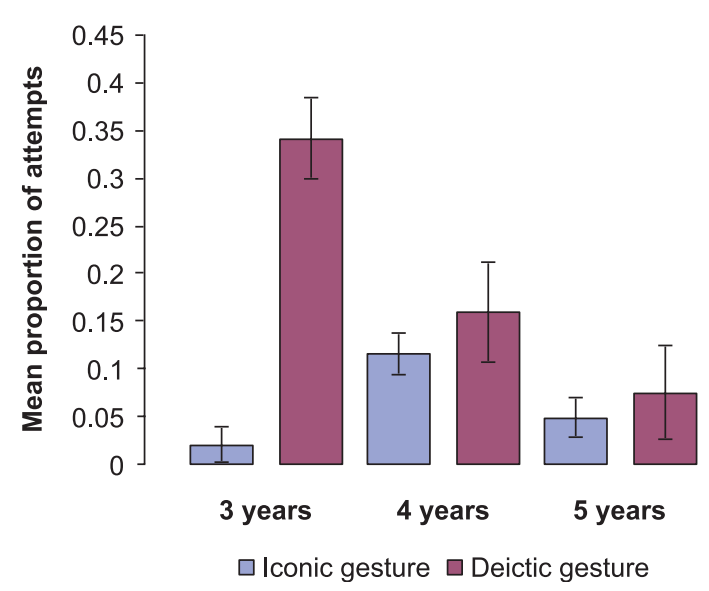

Figure 3 Mean proportion of disambiguation attempts made using speech and deictic or iconic gesture in the three age groups (error bars show standard error).

tests showed that the age groups differed significantly in their use of these styles of disambiguation (deictic gesture + speech: $\chi^{2}=13.27, d f=2, p<.001$; iconic gesture + speech: $\left.\chi^{2}=11.10, d f=2, p<.004\right)$. Mann-Whitney tests showed that the 3-year-olds made significantly more disambiguation attempts using speech and deictic gestures than did the 4- $\left(U=129.50, n_{1}=25, n_{2}=17\right.$, $p<.016)$ and 5-year-olds $\left(U=94.50, n_{1}=25, n_{2}=19\right.$, $p<.001)$. The difference between the 4- and the 5-yearolds was not significant $\left(U=113.50, n_{1}=17, n_{2}=19\right.$, $p<.065, n s)$.

With respect to the disambiguation attempts made using speech and iconic gestures, Mann-Whitney tests showed that the 4-year-old children made significantly more attempts of this kind than did the 3-year-old children ( $U=100.50, n_{1}=17, n_{2}=25, p<.001$, see Figure 3). The difference between the 4- and the 5-year-old children was also significant ( $U=91.00, n_{1}=17, n_{2}=19, p<.013$ ). The difference between the 3- and the 5-year-olds was not significant $\left(U=226.00, n_{1}=25, n_{2}=19, p<.364, n s\right)$.

\section{Children's use of speech and gesture during successful disambiguations}

Overall, the 5-year-olds disambiguated on average $41.9 \%$ of their attempts successfully, the 4-year-olds $33.6 \%$ and the 3-year-olds $20.3 \%{ }^{4}$ A Kruskal-Wallis test showed this to be a significant difference $\left(\chi^{2}=15.22, d f=2\right.$, $p<.0001)$. Mann-Whitney $U$-tests revealed that the 5-year-olds successfully disambiguated a significantly higher proportion of their overall disambiguation attempts than did the 3 -year-olds $\left(U=73.00, n_{1}=19\right.$, $\left.n_{2}=25, p<.0001\right)$, and that the difference between the 4- and 3-year-olds approached significance ( $U=134.00$, $n_{1}=17, n_{2}=25, p<.022$, respectively). If we consider only the proportion of successful verbal disambiguations,

\footnotetext{
${ }^{4}$ If we simply count whether the children eventually resolved the ambiguity (both meanings), the 5 -year-olds did so $79 \%$ of the time, the 4 -year-olds $49 \%$, and the 3 -year-olds $35 \%$.
}

the 5-year-olds were significantly better than both the 3 - and the 4-year-olds $\left(U=133.50, n_{1}=19, n_{2}=25\right.$, $p<.006$; and $U=65.00, n_{1}=19, n_{2}=17, p<.001$, respectively). The 4-year-olds did not differ from the 3 -year-olds when only verbal disambiguations were considered $\left(U=185.50, n_{1}=17, n_{2}=25, p<.24, n s\right)$. However, in terms of the number of successful verbal disambiguations accompanied by disambiguating iconic gestures, the 4-year-olds did differ significantly from the 3 -year-olds ( $\left.U=119.00, n_{1}=17, n_{2}=25, p<.003\right)$, but not from the 5-year-olds, although there was a trend $\left(U=100.00, n_{1}=17, n_{2}=19, p<.026, n s\right)$. None of the other comparisons relating to the successful disambiguations were significant. Thus, the data parallel the pattern we found when we analysed children's disambiguation attempts. Moreover, it becomes evident that the significant difference between the 4- and the 3-year-old children in terms of successful disambiguations is only revealed when we consider their successful disambiguations that include their use of iconic gesture.

Finally, there was a significant negative correlation between the proportion of successful attempts and the amount of attempted disambiguations accompanied by gesture $\left(r_{s}=-.410, N=61, p<.001\right)$, suggesting that the children who were most successful at disambiguating the senses were less likely to use gesture to do so.

\section{Discussion}

The findings from this study suggest clear developmental trends in children's use of gesture and speech to resolve lexical ambiguity. As has been reported elsewhere (e.g. Capirci et al., 2005; Iverson \& Goldin-Meadow, 2005; McEachern \& Haynes, 2004; Özçalişkan \& GoldinMeadow, 2005, 2009, Pizzuto \& Capobianco, 2005), we observed that children were negotiating cognitively demanding material initially through gesture, which was subsequently superseded by speech over time. Therefore our hypotheses were supported. The youngest children, the 3-year-olds, used the most ineffective means of disambiguation, in the form of unmodified nouns (e.g. bat) and deictic gestures, which were mostly uninformative in the experimental context. The 4-year-old children showed a greater awareness of the listener's indeterminacy associated with the ambiguities, as evidenced by their greater use of informative iconic gestures. Finally, the 5year-old children were the most competent communicators, relying mainly on the verbal channel to disambiguate the homonym senses. We discuss the results from each age group in turn and link our results to the literature on gesture and socio-cognitive development.

The 3-year-old children in the current study made fewer attempts to disambiguate verbally than did the 5-year-old children, and showed a tendency to make fewer verbal attempts than the 4-year-olds. Instead, this age group made more pointing gestures, both in the absence of speech as well as accompanying verbal 
disambiguation attempts, with this difference being significant between the 3- and the 5-year-olds. Pointing gestures are early signs of children's ability to engage in joint attention with an interlocutor (Bates et al., 1975; Liszkowski, Carpenter, Henning, Striano \& Tomasello, 2004; for a review see Tomasello, Carpenter \& Liszkowski, 2007). They are a powerful communicative tool because they act to initiate joint frames of reference and, in young infants, appear to form the basis of later language acquisition (Bates et al., 1975; Tomasello et al., 2007). Importantly, however, the deictic gestures used by the 3 -year-olds in the present study were almost exclusively gestures that were directed at the book that the addressee was unable to see. Therefore, although the use of deictic gestures is an effective strategy in most naturalistic settings, the strategy was ineffective in our experimental setting. This suggests that the 3-year-olds were not fully capable of adopting the addressee's perspective and thus did not understand that pointing in this particular communicative situation did not aid the attempt to distinguish the homonym's two alternative meanings. An ability to adopt an addressee's perspective for the purpose of effective referential communication necessitates the type of cognitive abilities measured by theory of mind tasks (Astington, 2003; Resches \& Pérez Pereira, 2007; Roberts \& Paterson, 1983; Roby \& Kidd, 2008). Therefore, since our 3-year-old children were below the age at which children generally pass such tasks (i.e. 4-5 years) (Wellman, Cross \& Watson, 2001), we suggest that the children's use of deictic gestures reflected a general inability to (i) understand the communication problem the lexical ambiguity caused for the addressee and therefore a general lack of awareness of the ambiguity itself, and (ii) identify the need to take the addressee's perspective.

Although the 3-year-old children produced the largest amount of deictic gestures, it is important to note that it was not the case that they were not producing iconic gestures in general. Rather, they showed a fairly frequent use of iconic gestures when asked what a certain entity, for example, a particular concept to which one of the homonyms referred, is used for, or what it can do. This supports previous research that has reported the use of iconic gestures in young children (e.g. Capirci et al., 2005; Capone, 2007; Pizzuto \& Capobianco, 2005). In a similar vein, it was not the case that the children did not know the homonym senses used in the experiment. Throughout the experiment the children displayed their knowledge of each sense when re-telling the story. Therefore the 3-year-old children's performance did not simply reflect a lexical gap, but rather an inability to appreciate the ambiguity caused by one-to-many formfunction mappings.

The 4-year-old children appeared to have begun to grasp the ineffectiveness of deictic gestures in the experimental context and used iconic gestures accompanied by speech to a significantly greater extent than did the 3-year-old children. This resulted in more success in the task overall. Importantly, the 4-year-olds also used more iconic gestures accompanied by speech than did the 5year-olds. Note that, like the 3-year-olds, the 4-year-old children were able to produce relevant linguistic items to refer to the concepts signified by the homonyms when questioned about them in a different context (i.e. one that does not require the children to disambiguate), such as in response to questions about their functions or usage. This rules out the explanation that the 4-yearolds' higher gesture frequency found in this study can be explained in terms of lexical retrieval difficulties (Pine, Bird \& Kirk, 2007). Therefore, following the predictions of Goldin-Meadow $(2000,2002)$, and the literature on children's use of gesture in early language development (e.g. Capirci et al., 2005; Pizzuto \& Capobianco, 2005), we see the emergence of a skill in the gestural modality before we see it in verbal language. We suggest that this can be explained by a combination of variables.

First, in comparison to the 5-year-olds, the 4-year-old children are likely to be less linguistically sophisticated, such that their command of noun modification will be more tenuous than the older children's. Therefore, in the absence of the ability to coordinate their linguistic knowledge with the pragmatics of the communicative event, the 4-year-olds also relied more heavily on the use of iconic gestures to resolve the ambiguity. Second, the 4-year-old children's use of iconic gestures in their disambiguation attempts is also suggestive of a better understanding of the concept of homonymy than was demonstrated by the 3-year-olds. The literature on the acquisition of homonymy has consistently shown that children do not accept non-dominant senses of homonyms until 4 years. Doherty (2000) has argued this is due to their better theory of mind abilities, whereas Garnham et al. (2000) argued that it reflects better executive functioning. The precise explanation for this is beyond the scope of this paper; however, at issue here is the mechanism that underlies the development of children's metalinguistic awareness. That is, there must be a decoupling of symbol and referent, such that the child comes to understand the arbitrary relationship between the two. Homonyms therefore provide a special test case to study children's metalinguistic and therefore symbolic development, since one-to-many form-meaning mappings expose aspects of language as being truly symbolic and arbitrary. The 4-year-olds' more frequent use of iconic gestures in the present study shows the process of decoupling in action: unlike the 3-year-olds, the 4-yearold children were able to abstract away from the referent and symbolize it using iconic gestures. ${ }^{5}$

The 5-year-old children were significantly more likely than the 3- and 4-year-old children to make purely verbal disambiguation attempts. In addition, they also

\footnotetext{
${ }^{5}$ Although the 4-year-olds used significantly more iconic gestures than did the 3-year-olds, it must be noted that their frequency was still only at around $11 \%$. In general, for children around this age gesture use will always be less frequent than spoken language use. Therefore we suggest that although the frequency of iconic gestures was low overall, the differences observed between the age groups are developmentally significant.
} 
showed a tendency to be more successful than both the 3- and the 4-year-old children in disambiguating the respective concepts successfully, although the difference between the 4- and the 5-year-old children did not reach significance. Out of all successful disambiguations, the 5year-old children produced a significantly greater proportion of purely verbal disambiguations than the 3-year-olds, and provided numerically more successful verbal disambiguations than did the 4-year-olds. Unlike the 4-year-olds, however, the 5-year-olds did not rely on iconic gestures as a means of disambiguation, presumably because, unlike the 4-year-olds, they were able to coordinate their linguistic knowledge with the pragmatic requirements of the experimental situation. That is, the 5-year-old children did not have to rely on gesture as a cognitive scaffold.

It is important to emphasize that we are not suggesting that gesture plays no part in language acquisition after the age of 5 years. Indeed, a similar study by Holler and Beattie (2003) showed that adults use gesture to disambiguate homonym senses. Instead, we suggest that, consistent with the notion that children use gesture to negotiate cognitively demanding material, children's use of gesture will vary according to the specific task at hand and communicative situation. Likewise, we are not suggesting that the pattern of gestural behaviour observed in the current study is necessarily exclusive to ambiguity resolution. It could, of course, be that the findings reflect a more general developmental pattern, but the present findings do not allow us to draw such general conclusions. What they do allow us to determine with some certainty, however, is how children at a certain age range use gesture and speech to negotiate lexical ambiguity.

Overall, our results are consistent with the suggestion that there is a tight coupling between gesture and verbal systems during language development. Our results complement the literature on young infants' use of gesture during early language development (e.g. Capirci et al., 2005; Iverson \& Goldin-Meadow, 2005; McEachern \& Haynes, 2004; Özçalişkan \& Goldin-Meadow, 2005; Pizzuto \& Capobianco, 2005) and the literature on older children's use of gesture at transitional stages of learning (e.g. Broaders et al., 2007; Church \& Goldin-Meadow, 1986; Pine et al., 2004). That is, we observed that children used gesture to negotiate ambiguity before they were able to do so in speech. As such, we suggest that the 4year-olds' use of iconic gesture marked their awareness of homonymy as communicatively problematic, and eased their transition into becoming capable of negotiating the ambiguity using speech.

The particular effect could be interpreted in a number of ways. First, following Goldin-Meadow (2000, 20002), the 4-year-old children may be using gesture as a 'cognitive crutch' by distributing the computational burden associated with negotiating lexical ambiguity through the gestural and verbal channels before they are able to do so using only speech. This first explanation is purely cognitive. Alternatively, the children's use of gesture may also have been interactionally motivated. For example, the 4-year-olds may have drawn upon iconic gestures slightly more because their verbal disambiguation skills were not as sophisticated as those of the 5-year-olds. This would suggest that these children used iconic gestures with the intent to produce utterances for the addressee that are as clear and unambiguous as possible. The fact that the 3-year-olds do not show the same gestural behaviour could be explained through their less developed interactional and perspective-taking skills, and therefore an inability to appreciate that gesture can clarify speech and benefit the listener. Future studies are needed to identify the contributions of cognitive and interactional processes to children's use of gesture in development.

There are several future avenues of investigation. First, children's ability to anticipate potential communicative problems will be reliant on their ability to understand the perspective of their interlocutor. Future similar research could consider testing children on perspectivetaking tasks, such as, for instance, theory of mind tasks. Second, this same task could be used to investigate children's awareness of, and ability to resolve, syntactic ambiguities. For instance, much recent research has investigated children's comprehension of prepositional phrase ambiguity, such as The woman waved to the man with the flag, where the flag can be construed as being possessed by either the subject or object of the sentence (Kidd \& Bavin, 2005, 2007; Snedeker \& Trueswell, 2004). If, as in the current study, children use gesture to disambiguate syntactic ambiguity, we would expect to see them do so before they were able to do so using only speech. Since children do not begin to show explicit awareness of syntactic ambiguity until around the age of 7-8 years (Cairns et al., 2004; Keil, 1980), we would predict that this would be precisely the kind of task where older children would use gesture.

Overall, the results of the current study add to a growing body of literature that highlights the important role of gesture to language development. We have shown that children make use of gesture in different ways when attempting to resolve lexical ambiguity, and have suggested that this is reflective of their cognitive development. The results underscore the importance of observing multiple communicative modalities during language development, suggesting that, just like in early language development, children make liberal use of the gestural channel to scaffold communicative exchange when the communicative task may overburden or overstretch the capabilities of their verbal system.

\section{Appendix}

\section{Story for homonym pair 'glasses' (i.e. drinking glasses and spectacles)}

Page 1: Georgewas eating his tea, whilst watching television. 
Page 2: When he finished eating, George went to wash up all the plates and glasses (drinking glasses).

Page 3: Suddenly there was a loud bang, shaking the glasses (spectacles).

Page 4: The glasses (spectacles) fell and hit the glasses (drinking glasses).

\section{Story for homonym pair 'mouse' (i.e. animal mouse and computer mouse)}

Page 1: Mark wasdoing homeworkon the computer(picture shows computer mouse).

Page 2: He got bored and decided to play with his mouse (animal mouse).

Page 3: Suddenly the mouse (animal mouse) jumped out of his hands.

Page 4: Mark turned and found the mouse (animal mouse) sat on the mouse (computer mouse).

\section{Acknowledgements}

We would like to thank Susie McCready and Sivan Shtrosberg for initial help with testing, and Wendy Symes, Katie Wilkin, and Rachael King for help with coding the data.

\section{References}

Acredolo, L., \& Goodwyn, S. (1988). Symbolic gesturing in normal infants. Child Development, 59, 450-466.

Alibali, M.W., Kita, S., \& Young, A. (2000). Gesture and the process of speech production: we think, therefore we gesture. Language and Cognitive Processes, 15, 593-613.

Astington, J.W. (2003). Sometimes necessary, never sufficient: false-belief understanding and social competence. In B. Repacholi \& V. Slaughter (Eds.), Individual differences in theory of mind: Implications for typical and atypical development (pp. 13-38). Hove: Psychology Press.

Backsheider, A., \& Gelman, S. (1995). Children's understanding of homonyms. Journal of Child Language, 22, 107-127.

Bates, E. (1976). Language and context: The acquisition of pragmatics. New York: Academic Press.

Bates, E., Benigni, L., Bretherton, I., Camaioni, L., \& Volterra, V. (1979). The emergence of symbols: Cognition and communication in infancy. New York: Academic Press.

Bates, E., Camaioni, L., \& Volterra, V. (1975). The acquisition of performatives prior to speech. Merrill Palmer Quarterly, 21, 205-226.

Bavelas, J.B. (2005). The two solitudes: reconciling social psychology and language and social interaction. In K. Fitch \& R. Sanders (Eds.), Handbook of language and social interaction (pp. 179-200). Mahwah, NJ: Erlbaum.

Branigan, H.P., McLean, J.F., \& Jones, M.W. (2005). A blue cat or a cat that is blue? Evidence for abstract syntax in young children's noun phrases. In A. Brugos, M.R. ClarkCotton, \& S. Ha (Eds.), The proceedings of the 29th annual Boston University conference on language development (pp. 109-121). Somerville, MA: Cascadilla Press.
Broaders, S.C., Cook, S.W., Mitchell, Z., \& Goldin-Meadow, S. (2007). Making children gesture brings out implicit knowledge and leads to learning. Journal of Experimental Psychology: General, 136, 539-550.

Cairns, H.S., Waltzman, D., \& Schlisselberg, G. (2004). Detecting the ambiguity of sentences: relationship to early reading skill. Communication Disorders Quarterly, 25, 68-78.

Capirci, O., Contaldo, A., Caselli, M.C., \& Volterra, V. (2005). From action to language through gesture: a longitudinal perspective. Gesture, 5, 155-177.

Capirci, O., Iverson, M.J., Montanari, S., \& Volterra, V. (2002). Gestures, sign, and words in early language development: the role of linguistic input. Bilingualism, Language, and Cognition, 5, 25-37.

Capirci, O., Iverson, J., Pizzuto, E., \& Volterra, V. (1996). Gestures and words during the transition to two-word speech. Journal of Child Language, 23, 645-673.

Capirci, O., Montanari, S., \& Volterra, V. (1998). Gestures, signs, and words in early language development. In J.M. Iverson \& S. Goldin-Meadow (Eds.), The nature and functions of gesture in children's communication (pp. 45-60). San Francisco, CA: Jossey-Bass Publishers.

Capirci, O., \& Volterra, V. (2008). Gesture and speech: the emergence and development of a strong and changing partnership. Gesture, 8, 22-44.

Capone, N. (2007). Tapping toddlers' evolving semantic representation via gesture. Journal of Speech-Language-Hearing Research, 50, 732-745.

Capone, N., \& McGregor, K. (2004). Gesture development: a review for clinical and research practices. Journal of Speech, Language, and Hearing Research, 47, 173-186.

Church, R.B., \& Goldin-Meadow, S. (1986). The mis-match between gesture and speech as an index of transitional knowledge. Cognition, 23, 43-71.

Clark, Eve V. (1993). The lexicon in acquisition. Cambridge: Cambridge University Press.

Corballis, M.C. (2002). From hand to mouth - The origins of language. Princeton, NJ: Princeton University Press.

Diessel, H. (2004). The acquisition of complex sentences. Cambridge: Cambridge University Press.

Doherty, M.J. (2000). Children's understanding of homonymy: metalinguistic awareness and false belief. Journal of Child Language, 27, 367-392.

Ekman, P., \& Friesen, W.V. (1969). The repertoire of nonverbal behavior: categories, origins, usage and coding. Semiotica, 1, 49-98.

Ferreira, V.S., Slevc, L.R., \& Rogers, E.S. (2005). How do speakers avoid ambiguous linguistic expressions? Cognition, 96, 263-284.

Garnham, W.A., Brooks, J., Garnham, A., \& Ostenfeld, A-M. (2000). From synonyms to homonyms: exploring the role of metarepresentation in language understanding. Developmental Science, 4, 428-441.

Gentilucci, M., \& Corballis, M.C. (2006). From manual gesture to speech: a gradual transition. Neuroscience and Biobehavioral Reviews, 30, 949-960.

Goldin-Meadow, S. (2000). Beyond words: the importance of gesturetoresearchersandlearners. Child Development, 71,231-239.

Goldin-Meadow, S. (2002). Constructing communication by hand. Cognitive Development, 17, 1385-1405.

Goldin-Meadow, S., Nusbaum, H., Kelly, S., \& Wagner, S. (2001). Explaining math: gesturing lightens the load. Psychological Science, 12, 516-522. 
Goldin-Meadow, S., \& Singer, M.A. (2003). From children's hands to adults' ears: gesture's role in teaching and learning. Developmental Psychology, 39, 509-520.

Holler, J., \& Beattie, G. (2003). Pragmatic aspects of representational gestures: do speakers use them to clarify verbal ambiguity with the listener? Gesture, 3, 127-154.

Iverson, J., Capirci, O., \& Caselli, M.C. (1994). From communication to language in two modalities. Cognitive Development, 9, 23-43.

Iverson, J.M., \& Goldin-Meadow, S. (2005) Gesture paves the way for language development. Psychological Science, 16, 367-371.

Karmiloff-Smith, A. (1985). Language and cognitive processes from a developmental perspective. Language and Cognitive Processes, 1, 61-85.

Karmiloff-Smith, A. (1986). From meta-process to conscious access: evidence from children's metalinguistic and repair data. Cognition, 23, 95-147.

Keil, F. (1980). Development of the ability to perceive ambiguities: evidence for task specificity of a linguistic skill. Journal of Psycholinguistic Research, 9, 219-229.

Kemp, N., Lieven, E., \& Tomasello, M. (2005). Young children's knowledge of the 'determiner' and 'adjective' categories. Journal of Speech, Language, and Hearing Research, 48, 592-609.

Kendon, A. (1985). Some uses of gesture. In D. Tannen \& M. Saville-Troike (Eds.), Perspectives on silence (pp. 215-234). Norwood, NJ: Ablex.

Kendon, A. (2004). Gesture: Visible action as utterance. Cambridge: Cambridge University Press.

Kidd, E., \& Bavin, E.L. (2005). Lexical and referential cues to sentence interpretation: an investigation of children's interpretations of ambiguous sentences. Journal of Child Language, 32, 855-876.

Kidd, E., \& Bavin, E.L. (2007). Lexical and referential constraints on on-line spoken language comprehension: a comparison of adults and primary-school age children. First Language, 27, 29-52.

Kidd, E., Brandt, S., Lieven, E., \& Tomasello, M. (2007). Object relatives made easy: a crosslinguistic comparison of the constraints influencing young children's processing of relative clauses. Language and Cognitive Processes, 22, 860 897.

Kidd, E., \& Cameron-Faulkner, T.R. (2008). The acquisition of the multiple senses of with. Linguistics, 46, 33-62.

Kohler, E., Keysers, C., Umilità, M., Fogassi, L., Gallese, V., \& Rizzolatti, G. (2002). Hearing sounds, understanding actions: action representation in mirror neurons. Science, 297, 846-848.

Liszkowski, U., Carpenter, M., Henning, A., Striano, T., \& Tomasello, M. (2004). Twelve-month-olds point to share attention and interest. Developmental Science, 7, 297307.

McEachern, D., \& Haynes, W.O. (2004). Gesture-speech combinations as a transition to multiword utterances. American Journal of Speech-Language Pathology, 13, 227-235.

McNeill, D. (1992). Hand and mind - What gestures reveal about thought. Chicago, IL: University of Chicago Press.

Markman, E. (1990). Constraints children place on word meanings. Cognitive Science, 14, 57-77.
Mayberry, R., \& Nicoladis, E. (2000). Gestures reflect language development: evidence from bilingual children. Current Directions in Psychological Science, 9, 192-196.

Mintz, T., \& Gleitman, L. (2002). Adjectives do really modify nouns: the incremental and restricted nature of early adjective acquisition. Cognition, 84, 267-293.

Özçalişkan, S., \& Goldin-Meadow, S. (2005). Gesture is at the cutting edge of early language development. Cognition, 96, B101-B113.

Özçalişkan, S., \& Goldin-Meadow, S. (2009). When gesturespeech combinations do and do not index linguistic change. Language and Cognitive Processes, 24, 190-217.

Perry, M., Church, R., \& Goldin-Meadow, S. (1988). Transitional knowledge in the acquisition of concepts. Cognitive Development, 3, 359-400.

Peters, A., \& Zaidel, E. (1980). The acquisition of homonymy. Cognition, 8, 187-207.

Pine, K.J., Bird, H., \& Kirk, E. (2007). The effects of prohibiting gestures in children's lexical retrieval ability. Developmental Science, 10, 747-754.

Pine, K.J., Lufkin, N., \& Messer, D.J. (2004). More gestures than answers: children learning about balance. Developmental Psychology, 40, 1059-1067.

Pizzuto, E., \& Capobianco, M. (2005). The link and differences between deixis and symbols in children's early gestural-vocal system. Gesture, 5, 179-199.

Reches, M., \& Pérez Pereira, M. (2007). Referential communication abilities and theory of mind development in preschool children. Journal of Child Language, 34, 21-52.

Rizzolatti, G., \& Arbib, M. (1998). Language within our grasp. Trends in Neuroscience, 21, 188-194.

Roberts, R.J., \& Patterson, C.J. (1983). Perspective taking and referential communication: the question of correspondence reconsidered. Child Development, 54, 1005-1014.

Roby, A., \& Kidd, E. (2008). An investigation of the referential communication skills of children with imaginary companions. Developmental Science, 11, 531-540.

Shultz, T.R., \& Pilon, R. (1973). Development of the ability to detect linguistic ambiguity. Child Development, 44, 728-733.

Snedeker, J., \& Trueswell, J.C. (2004). The developing constraints on parsing decisions: the role of lexical-biases and referential scenes in child and adult sentence processing. Cognitive Psychology, 49, 238-299.

Taylor, M., \& Carlson, S. (1997). The relation between individual differences in fantasy and theory of mind. Child Development, 68, 436-455.

Thurnham, A.J., \& Pine, K. (2006). The effects of single and dual representations on children's gesture production. Cognitive Development, 21, 46-59.

Tomasello, M., Carpenter, M., \& Liszkowski, U. (2007). A new look at infant pointing. Child Development, 78, 705-722.

Trueswell, J.C., Sekerina, I., Hill, N.M., \& Logrip, M.L. (1999). The kindergarten-path effect: studying on-line sentence processing in young children. Cognition, 73, 89-134.

Wellman, H.W., Cross, D., \& Watson, J. (2001). Meta-analysis of theory of mind development: the truth about false belief. Child Development, 72, 655-684.

Received: 31 March 2008

Accepted: 12 August 2008 